\title{
Uma nova velha história: sobre censura e literatura LGBT+
}

\author{
A New Old Story: On Censorship and LGBT+ literature \\ Una nueva vieja historia: sobre censura y literatura LGBT+ \\ Renata Barreto Malta* \\ Carina Luisa Ochi Flexor \\ Aianne Amado Nunes Costa
}

\section{Resumo}

Se, por um lado, o objeto livro se conformou historicamente como instrumento de poder hegemônico, por outro, corrobora, a partir da pluralidade de conteúdos, para a existência, não apenas ficcional, de identidades múltiplas. De encontro a essa premissa, a censura contra conteúdo LGBT+ para crianças e adolescentes ganha contorno hodierno durante a Bienal do livro do Rio de Janeiro. Com o objetivo de interpretar a resposta do público acerca do episódio, sua relação com aspectos socioculturais e, principalmente, em que medida o ambiente livresco se reverbera nessas postagens, propomos uma análise de redes semânticas do corpus selecionado. Para a fundamentação teórica, baseamo-nos na historiografia do livro e da literatura, nos estudos culturais e nos estudos de gênero. Como resultado, em suma, discutimos quatro temáticas centrais que apontam para o interesse pela leitura do conteúdo distribuído ou seu rechaço; a relação entre educação e vigilância direcionada às crianças; o sentimento de pertencimento por parte da comunidade LGBT+; a moral cristã como argumento contrário à ação.

Palavras-chave: literatura infanto-juvenil, LGBT+, censura e contra censura, análise semântica.

Abstract

If, on the one hand, the book as an object has historically been wielded as an instrument of hegemonic power, on the other, given its plurality of contents, it corroborates the existence, not only fictional, of multiple identities. Against this premise, the censorship of LGBT+ content for children and teenagers gains new dimensions during the Bienal in Rio de Janeiro. In order to interpret the response of young audiences to the incident, its relationship with socio-cultural aspects and, mainly, to what extent the literary environment is reflected in those posts, we propose an analysis of semantic networks within the selected corpus. For the theoretical approach, our argument is supported by literary and book historiographies, cultural studies and gender studies. As a result, in short, we have analyzed four central themes, called clusters: some users' desire to read the distributed content and the rejection on the part of non-supporters; the relationship between education and surveillance directed at children; the feeling of belonging

\section{Resumen}

Si por un lado el objeto libro se ha conformado históricamente como instrumento de poder hegemónico, por otro, contribuye, a partir de la pluralidad de contenidos, para la existencia, no solamente ficcional, de identidades múltiples. Contrariando esa premisa, la censura contra contenido LGBT+ para niños y adolescentes gana contorno hodierno, durante la Bienal del libro de Rio de Janeiro. Con el objetivo de interpretar la respuesta del público sobre el episodio, su relación con aspectos socioculturales $y$, principalmente, en qué medida el ambiente libresco se reverbera en esas publicaciones, proponemos un análisis de redes semánticas del corpus seleccionado. Para la fundamentación teórica, nos basamos en la historiografía del libro y de la literatura, en los estudios culturales y en los estudios de género. Como resultado, en suma, discutimos cuatro temáticas centrales que apuntan al interés por la lectura del contenido distribuido o por su rechazo; la relación entre educación y vigilancia direccionada a los niños; el

\footnotetext{
"Universidade Federal de Sergipe, Aracaju, SE, Brasil. (Dorcid.org/0000-0002-7414-9081. E-mail: renatamaltarm@ gmail.com

** Universidade de Brasília, Brasília, DF, Brasil. (Dorcid.org/0000-0001-9597-8922. E-mail: cflexor@gmail.com

*** Universidade Federal de Sergipe, Aracaju, SE, Brasil. (Dorcid.org/0000-0002-6754-2715. E-mail: aianne_amado@hotmail.com
} 
within the LGBT + community; and Christian morality as an argument against the action.

Keywords: children and youth literature, LGBT+ content, censorship and against censorship, semantic networks. sentimiento de pertenencia por parte de la comunidad LGBT+, la moral cristiana como argumento contrario a la acción.

Palabras-clave: Literatura infantojuvenil; LGBT+; Censura/contra censura; Análisis semántica.

\section{Index librorum prohibitorum: configurações contemporâneas}

As relações de poder entrelaçam-se ao objeto livresco e se materializam no ato da leitura. Dessa prática, constroem-se espaços de sociabilidade, mais ou menos tangíveis, que dão forma ao aspecto político ali contido. É no campo ideológico - compreendido como estrutura de pensamento e avaliação de mundo que norteia as experiências sociais - que o saber se constitui repleto de antagonismos e a serviço de interesses contraditórios. Se a leitura, antecedida pelo objeto livro e pelo uso estético da linguagem escrita, promove a capacidade crítica e, em alguma medida, a emancipação do ser social, as ideias de verdade e universalidade que caracterizam o saber atendem à manutenção do sistema hegemônico e refutam pluralidades interpretativas.

É nesse campo de disputas que a dominação, interdição e coerção se descortinam, tolhendo certos modos de pensar e atuar no mundo. Nesse sentido, a censura ocupou as páginas da história para evitar a palavra escrita antagônica, materializada de diversas formas, mas invariavelmente promovendo violência simbólica. Como efeito rebote, suas armas, especialmente em momentos de repressão institucionalizada, fomentaram a busca por uma produção literária polissêmica, capaz de driblar os censores mais vorazes.

Entre os universos literários, a literatura infantojuvenil se mostrou um terreno frutífero para a transposição de sentidos, possibilitando a germinação de ideias contra hegemônicas em sua pluralidade. A exploração do campo por autores e autoras que propuseram a reflexão de problemáticas sociais em tempos de repressão significou não apenas driblar a censura, como também romper com a visão instrumental que marcou o campo, alinhada a sua utilidade para a aprendizagem escolar. Essa perspectiva utilitária e moralizante - considerando a relação intrínseca entre escola e Igreja - ainda norteia boa parte da produção literária infantojuvenil brasileira, e é com base nesses preceitos que determinados temas sociais encontram forte resistência para ocupar os livros.

Narrativas que discutem orientação sexual e expressões não binárias de gênero esbarram em obstáculos, especialmente para compor as páginas destinadas a crianças e a adolescentes. $\mathrm{O}$ enfrentamento a essas barreiras desbordou, recentemente, uma série de títulos literários voltados a esse público, antes impensado, dando forma a uma insólita arena que sustenta embates de cunho político.

Sabemos que a ficção se alimenta do cotidiano, assim como serve de inspiração para as práticas sociais. Desse encontro, qualquer semelhança não é mera coincidência. Em setembro de 2019, durante a Bienal do Livro, o prefeito do Rio de Janeiro Marcelo Crivella protagoniza um ato de censura contra a obra Vingadores, a cruzada das crianças, por conter conteúdo LGBT+ considerado por ele impróprio para o público infantil. No mesmo dia, Felipe Neto - um dos maiores influenciadores digitais com conteúdo direcionado ao público infantojuvenil - protesta contra a censura e divulga um vídeo em seu canal do Youtube informando, com tom de revolta, que distribuiria gratuitamente, a quem se interessasse, todo o estoque dos principais livros disponibilizados na Bienal, cujas narrativas estivessem focadas na temática (Neto, 2019, 5,38m).

Uma das obras distribuídas, Ninguém nasce herói, do escritor Eric Novello, publicado pela editora Seguinte, tem como cenário um Brasil repressor que, liderado por fundamentalistas religiosos, considera o simples ato de distribuir livros nas ruas um sinal de rebeldia contra o sistema. $\mathrm{O}$ tom alarmista que a narrativa ficcional instaura encontra vestígios, ou traços ainda mais visíveis, numa realidade atual, com a ascensão do conservadorismo. Se na história as respostas - favoráveis ou contra a censura e repressão - são verbalizadas pelos transeuntes, no 
mundo real elas ganham holofotes nas redes digitais. $\mathrm{O}$ vídeo postado por Felipe Neto como manifesto à censura provocou a reação em forma de comentários de mais de 36 mil pessoas, entre tantos outros desdobramentos motivados pela ação.

Diante desse cenário, vimo-nos, como critério metodológico, instigadas a realizar uma análise semântica dos discursos que ali se instauraram, propondo-nos a uma discussão teoricamente embasada em autores dos campos da historiografia do livro e da literatura, dos estudos culturais e dos estudos de gênero - entre outros que dialogam com o objeto estudado -, com o objetivo de compreender as disputas de poder em jogo, alicerçadas em aspectos socioculturais. O objeto livro, suporte das narrativas literárias que antecipa o ato da leitura, está no centro dessa discussão.

\section{O livro, a literatura e a dimensão política da leitura}

Livros não mudam o mundo, quem muda o mundo são as pessoas. Os livros só mudam as pessoas.

Mario Quintana (2006, p. 31)

Com a delicadeza que lhe é peculiar, Mário Quintana deixa escapar as relações de poder que se tecem silenciosas nas práticas da leitura, apontando para a relevância do objeto livresco e a produção verbovisual que carrega em si. Refletir sobre as relações que são tecidas entre livro e literatura é, antes, reconhecer as dimensões de poder contidas no saber e, sobretudo, o aspecto político implícito nas práticas da leitura. Acerca dessa questão, Manguel, em entrevista ao Fronteiras do Pensamento, sinaliza para o fato de que "ler sempre é um ato de poder", "uma das razões pelas quais o leitor é temido em quase todas as sociedades" (Manguel, 2018, 5,34 min).

Notadamente, o livro fez-se espaço-tempo e materialização de contravenções desde o seu aparecimento, uma vez que se verifica que a associação do objeto ao suporte papel não passa de um recorte europeu que reduziu uma demanda cultural a uma autocracia da forma, materialidade e modo de pensar. Já a literatura, em especial a brasileira voltada para o universo infantojuvenil, teceu sua história sempre emaranhada em estruturas, de alguma forma reguladoras, como o estado, a escola e o próprio mercado editorial (Lajolo e Zilberman, 2017). Se os dois primeiros ajudaram a demarcar os caminhos do campo por meio de instrumentos diretivos de órgãos governamentais, é na esfera comercial do livro que a literatura infantojuvenil encontra seu espaço e, enquanto produto de consumo midiaticamente promovido, é, ainda, atravessada pelos perigos que os discursos didático e ideológico dos órgãos centrais da educação e cultura podem imprimir (Lajolo e Zilberman, 2017, p. 59). O livro e a literatura, então, configuram-se como produções culturais que, ao passo que promovem a emancipação e a criticidade do leitor, criam também enquadramentos e fronteiras sociais, sendo alvo de censura e de políticas públicas sugestivas de formas de pensar, sentir, agir.

Nas páginas de nossa história, a produção literária e, consequentemente, a leitura estiveram, muitas vezes, vinculadas à coerção, interdição e censura, "a leitura está iluminada por uma fileira interminável de fogueiras de censores, dos primeiros rolos de papiro aos livros de nossa época" (Manguel, 2010, p. 315). Da Europa, de Stálin - que ordenou o fuzilamento de escritores e censurou publicações em nome de ideais socialistas - a Joseph Goebbels, na Alemanha nazista - que autorizou a queima de milhares de livros -, obras e autores foram condenados ao silêncio. Na América Latina, as ditaduras militares também implantaram instrumentos de censura à leitura. No Brasil de 1964, o golpe militar fez-se território de apreensão de livros, destruição de bibliotecas, perseguição (e morte) de autores, ataque às universidades por forças militares por subversão à ordem.

Produzindo seu próprio Index, ${ }^{1}$ a ditadura brasileira censurou obras que eram consideradas subversivas e, em 1968, com o AI-5, a repressão se intensificou com a censura prévia. Autores cujas

\footnotetext{
${ }^{1}$ Index Librorum Prohibitorum refere-se ao índice dos livros proibidos, condenando obras consideradas heréticas e de teor subversivo aos olhos da Igreja (Manguel, 2018).
} 
obras atravessavam temas como sexo e homossexualidade sofreram grande perseguição, tais como Adelaide Carraro, Cassandra Rios e Plínio Matos, rotulados de imorais e/ou promotores da desordem, conforme registra o site Memórias da Ditadura (Instituto Vladimir Herzog, s.d.).

De certo, todo esse cenário também acabou por se refletir na produção literária da época, uma vez que a autocensura repercutiu em produções que lançavam mão de figuras de linguagem para, nas entrelinhas, deixar escapar a intenção do autor. Conforme registram Moraes e Lajolo (1995, p. 52), "era preciso driblar a repressão. Jogar com as ambiguidades... com a polissemia". Assim, a literatura infantojuvenil, pela assimetria historicamente constituída em relação a outras produções nesse campo, foi o setor que conseguiu semear uma espécie de liberdade, "através do universo mágico dos livros infantis, puderam desacreditar os valores que sustentavam a política de linha dura dos militares, de certo modo induzindo uma geração a pensar por si e a desconfiar de ideias que matam" (Bordini, 1998, p. 38).

Tornaram-se representativos, nessa época, os trabalhos desenhados por Ana Maria Machado, Lygia Bojunga, Ruth Rocha, Marina Colasanti, Ziraldo, entre outros que, no limite da criatividade para burlar a censura, essas/esses escritoras(es) produziram uma literatura infantojuvenil que denunciava o momento histórico vivido, tornando-se relevantes no processo de construção da identidade e cultura brasileira. Entretanto, a discussão em torno da diversidade sexual e de gênero ainda permanecia praticamente em silêncio, emergindo mais significativamente apenas no final dos anos 1990 e início dos anos 2000. Editoras de renome começaram a apostar em obras que, de forma mais ou menos explícita, discutiam a homossexualidade e transgeneridade, como $O$ gato que gostava de cenoura, de Rubem Alves em 1999 e, no ano seguinte, o Menino ama menino, de Marilena Godinho. A partir daí, a lista não parou de crescer, abrindo espaço para a temática como gênero literário em grandes editoras e possibilitando o surgimento de editoras independentes especializadas na temática, como a Hoo, fundada em 2015.

Entretanto, é importante registrar que uma produção infantojuvenil datada do período da ditadura camuflou uma discussão social que, em alguma medida, remetia às relações de gênero, além de claramente desafiar a repressão. A bolsa amarela, da premiada escritora Lygia Bojunga conta a história de uma menina reprimida, Raquel, que esconde em uma bolsa amarela três vontades: a de ser grande, a de ser um garoto e a de ser escritora. Na narrativa, tomam forma temas de cunho social, como o machismo que estrutura a sociedade, a transgeneridade, $o$ aborto. O tom fantasioso da obra contribui para que essas questões permaneçam implícitas, fazendo ver mais claramente as transformações da menina, que ganha confiança e força para enfrentar o mundo e as lições de uma vida democrática.

Se a obra sobreviveu aos censores da ditadura militar, passadas mais de quatro décadas, dezenas de reedições e sua consolidação como clássico da literatura infantojuvenil, em agosto de 2019, o livro sofreu tentativa de censura por ser considerada ideologia de gênero (Oito livros..., 2019). Ainda que a censura não tenha se concretizado, o ato descortina a latente ameaça à livre expressão da atividade intelectual alicerçada no conservadorismo nos dias de hoje.

Assim como na esfera federal, também no âmbito estadual e municipal tem sido possível perceber tentativas de censura à literatura infantil e juvenil, sobretudo aquelas que tratam de temáticas que envolvem sexualidade e gênero. Em 2017, o livro Enquanto o sono não vem, de José Mauro Brant publicado pela Editora Rocco, foi recolhido das escolas públicas (Abrelivros, 2017). Em 2019, vimos a supressão do livro Queermuseu: cartografias da diferença na arte brasileira ${ }^{2}$ do acervo das bibliotecas públicas (Mendonça, 2017). Em fevereiro de 2020, o governo de Rondônia ordenou o recolhimento de livros tidos como inadequados para crianças e adolescentes, incluindo obras de escritores consagrados na literatura - como Mário de Andrade, Carlos Heitor Cony, Euclides da Cunha, Machado de Assis (ABL..., 2020).

Essas sucessivas tentativas de censura ao objeto livresco e à literatura inserem-se em um contexto maior, atravessado por outros fatores que acabam por corroborar o cerceamento e a restrição à leitura e ao conhecimento, bem como para o clima de ódio, intolerância e violência -

\footnotetext{
${ }^{2}$ A publicação é resultado da exposição de mesmo nome, que foi cancelada pelo Santander Cultural, em Porto Alegre (RS), após uma série de protestos nas redes sociais em 2017.
} 
em especial contra as denominadas minorias. Uma ação ainda mais repressiva ocorreu durante a Bienal do Livro de 2019. Fiscais da Secretaria Municipal percorreram os estandes do evento com a missão de recolher livros com temática LGBT+, considerados pelo prefeito da cidade, Marcelo Crivella, inadequados para o público infantojuvenil (Jucá, 2019). O foco foi o livro gráfico Vingadores, a cruzada das crianças, publicado no Brasil em 2016 pela Editora Salvat em parceria com a Panini Comics. Um beijo homoafetivo foi o motivo da ação. Mais tarde, a justiça proibiu a censura. Em poucas horas, todos os exemplares disponíveis haviam sido vendidos e o debate nas redes sociais havia se instaurado, demonstrando que as reações também se apresentam de forma imediata. Assim, as disputas que se formam nessa arena demandam discussão e análise e propomos realizá-la para este artigo.

\section{Questões metodológicas}

Considerando esse fato e seus desdobramentos como terreno de investigação, nossa trajetória empírica se desenha baseada em algumas premissas. Focamos nossas atenções na ação do digital influencer Felipe Neto - um dos mais influentes youtubers brasileiros junto ao público infantil e juvenil, com mais de 35 milhões de inscritos no seu canal -, não apenas por sua relevância na ambiência digital, mas, principalmente, porque a reação se materializou na distribuição gratuita de milhares de livros de temática LGBT+ durante a Bienal, extrapolando o ativismo digital.

Esses livros, embalados em plástico com a mensagem "livro impróprio para pessoas atrasadas, retrógradas e preconceituosas. Felipe Neto agradece a sua luta pelo amor, pela inclusão e diversidade", sinaliza para um duplo protesto - contra a censura ao objeto literário e ao ataque à comunidade LGBT+ - fazendo ecoar vozes dissonantes e concordantes no universo digital, em especial, no canal do youtuber.

Entre os espaços de disputa que envolvem a ação, entendemos estarem nas redes sociais digitais as informações e os dados mais completos para se compreender as linhas discursivas que ali se materializaram. A permanência e capacidade de registro dessas plataformas permitem um mapeamento amplo, apurado e preciso (Recuero, 2009). As possibilidades de escolha para seleção do corpus eram múltiplas e, nesse sentido, optamos pela seção de comentários do vídeo de divulgação da ação postado no canal de Felipe Neto, considerando que, por ser vinculada ao fato, todas as publicações fariam referência direta ao evento.

Para tanto, fizemos uso do módulo de informações e comentários da ferramenta Youtube Data Tools (Rieder, 2015) e levantamos todos os 36.519 comentários postados por usuários até a data da coleta, ${ }^{3}$ que foram organizados em uma planilha. Os comentários foram processados no programa WORDij, resultando em um mapeamento detalhado e factível do conteúdo analisado a partir de redes de palavras com maior ou menor relevância semântica. O programa criado por James Danowski (1993) captura a relação entre as palavras que constroem as mensagens, identificando os pares ou conjunto de palavras que mais se conectam, formando redes de significações análogas, denominadas de clusters. Utilizado em pesquisas anteriores no campo da comunicação social (Malta, Amado e Meirelles, 2019), o método propicia a visualização de um mapa de palavras que ilustra a estrutura de sentido do conteúdo analisado, possibilitando a observação de padrões, tendências e linhas de discurso.

Por fim, o levantamento foi importado para o software de análise de redes Gephi (Bastian et al., 2009) composto pelo layout ForceAtlas2, dando forma à rede geral dos termos. Cada palavra representada na rede forma um nó. $\mathrm{O}$ tamanho do nó denota sua força semântica, nós maiores significam um maior número de correlações - não necessariamente as palavras mais frequentes. A proximidade entre os nós indica o grau de correlação semântica e a sua centralidade na rede tem associação direta com o número de conexões. Os nós mais conectados entre si formam

\footnotetext{
${ }^{3}$ A pesquisa toma como base para as análises os comentários coletados até 4 de fevereiro de 2020 , deixando à margem os 378 mil likes e 48 mil deslikes, embora estes também representem reações do público aos fatos em questão.
} 
agrupamentos semânticos - clusters. Os achados dessa trajetória empírica, assim como as intepretações subsequentes, serão apresentados nos tópicos que seguem.

\section{Entre dados e discussões, entre censura e representação}

Para além dos dados empíricos, a partir da metodologia então delineada, entre os clusters identificados 4 discutiremos quatro temas que se constroem a partir das seguintes palavraschave: "livro/livros"; "criança/crianças"; "LGBT"; "amor/Deus". Para além desses, outros três importantes clusters - no que tange à força semântica -, fizeram-se presentes o primeiro, centrado na palavra "Parabéns"; o segundo, em "Pessoas/Mundo/Brasil"; e o último, em "Respeito". Ainda que estes tragam frutíferas interpretações, não apresentaremos tais análises por considerarmos que não se relacionam diretamente ao escopo deste artigo.

Entretanto, pontuamos que a análise dos comentários direcionados ao vídeo de um influenciador digital com tamanha inserção esbarra em uma dinâmica que é própria desse universo. Diferentemente da audiência comum, o fã é a parcela mais engajada de um público que sente necessidade de demonstrar seu apoio e compartilhar opiniões e experiências com seus ídolos ou outros fãs. Nesse sentido, é preciso considerar que, a partir da campanha presidencial de Jair Bolsonaro, Felipe Neto tem se mostrado ativo em discussões políticas, assumindo uma clara postura de oposição ao governo atual. Isso tem dispersado alguns adoradores, bem como angariado uma nova leva de fãs e antifãs, dispostos a demonstrar seu apoio ou reprovação a cada postagem.

De fato, o vídeo de que tratamos aqui é um dos que mais gerou interações no referido canal do youtuber - que poucas vezes ultrapassou a marca de 10 mil comentários -, permitidno notar que a disputa ideológica e política em questão despertou o interesse de usuários, levando-os a interagir e transformar suas interpretações. $O$ conteúdo dessas interações exige aprofundamento e embasamento teórico, movimento que realizaremos a seguir.

\section{Livro(s): protagonista ou coadjuvante?}

O cluster que se constitui a partir dos vocábulos "livro" e "livros" é, aparentemente, o que mais se espalha no mapa semântico analisado. De fato, ele se distribui em dois clusters, os quais foram ilustrados no mapa por cores diferentes e agrupados para análise. Essa constatação poderia reforçar o poder simbólico que o objeto carrega historicamente, "um poder incomparável de penetração e de irradiação" (Martin e Febvre, 1992, p. 15). No entanto, é preciso um olhar mais acurado. As múltiplas conexões que se constroem com o termo se justificam, já que ele está no centro da ação, tanto de censura, como de protesto, que motiva os comentários que compõem o corpus. Desse modo, vemo-nos instigadas a observar, por meio da análise semântica proposta, quais sentidos ali emergem.

Nesse movimento analítico, a palavra "livro" - no singular e no plural - relaciona-se basicamente a dois universos discursivos. O primeiro se associa a argumentos mercadológicos, tendo a palavra "dinheiro" grande força semântica que, relacionada aos verbos "gastar", "comprar", "ganhar" - em diferentes conjugações - produz os argumentos nesses nós. É certo que a dimensão comercial compõe o jogo simbólico da história do objeto livresco. Em entrevista, Chartier (2004) destaca que "é responsabilidade dos intelectuais, dos meios de comunicação, dos editores, assegurar a transmissão de um saber sobre o mundo [...] para que as pessoas não sejam totalmente submetidas às leis do mercado". O ato de comprar livros para distribuí-los ao público interessado estaria, assim, envolto nessa lógica. Também se conectam a esse nó termos como "propaganda", "mídia”, e "fama” e o verbo "aparecer". Tais conexões nos levam a interpretar que certos argumentos posicionam a ação de protesto realizada pelo youtuber como forma de autopromoção.

\footnotetext{
${ }^{4}$ Devido aos limites de formatação do artigo, optamos por disponibilizar os clusters visualmente, que podem ser observados em diferentes cores no mapa geral disponível em: https://bit.ly/35Bunpo.
} 
É sabido que o Youtube se constituiu como uma plataforma favorável para a emergência de rentáveis negócios, especialmente para os produtores de conteúdo, chamados youtubers, por potencialmente mobilizarem a audiência. Para alguns, a visibilidade é tamanha que se tornam uma espécie de celebridades. O canal de Felipe Neto está entre os três com maior número de inscritos no país, despontando como uma das personalidades brasileiras mais influentes no universo digital.

Nesse tocante, o espaço em que a censura se conformou - uma Bienal do livro -, assim como o próprio protesto de um jovem que fala para jovens, por si, já se configura como um sinal de resistência que, se se recobre estratégias de autopromoção ou não, não invalida seu papel subversivo. Ademais, sobre a associação de "livro" e "promoção", pouco depois da tentativa de censura, todos os exemplares da história em quadrinhos em questão se esgotaram.

O segundo universo discursivo, por sua vez, faz referência ao conteúdo literário. Aqui, percebemos duas correntes, uma de pessoas interessadas no material literário, materializado pelos verbos "quero", "queria" e "pegar", em nós que se conectam ao termo "Bienal". Também encontramos a palavra "moro" (do verbo morar) relacionada a residentes do "Rio de Janeiro" (ou "RJ") que possuem interesse na ação, ou "longe" da cidade e, portanto, sem acesso ao material distribuído. As relações com as expressões "pena" e "infelizmente" reforçam o pesar pelo não acesso aos livros distribuídos pelo youtuber. Entendemos que essas mensagens, além de seu teor de apoio, também significam um interesse pela leitura de conteúdo LGBT+ possivelmente potencializado pela ação do youtuber.

A outra corrente discursiva rechaça o conteúdo distribuído, expresso em termos como "lixo", "verme" e "bobagem". É justamente nesse último sentido que o cluster formado pela palavra "livro" conecta-se ao constituído por "criança" como termo central, quando o conteúdo é questionado como apropriado ou não para o público infantil, e sua relação com a "educação" e com a "cultura". Sobre essas conexões, trataremos acuradamente ao discutir o próximo cluster.

Ao buscar termos que remetem ao universo literário especificamente, os achados foram pouco representativos. A palavra "Bienal" aparece com pouca força semântica, construindo apenas nós relacionados à vontade do público interessado em ganhar livros e à cidade do Rio de Janeiro. Nada foi observado sobre os títulos dos livros de temática LGBT+ distribuídos pelo youtuber, nomes de escritores, outros manifestos ocorridos por parte de escritores ou de organizadores da feira, nem mesmo o nome da obra censurada, citada através do termo "HQ" que, em última instância, faz notar o papel que cumprem - para o público infantojuvenil - as narrativas em quadrinhos e, em especial, o papel das narrativas visuais como produção poética e sensível. Todos esses silenciamentos são significativos, pois demonstram a ausência desses referenciais, especialmente para o público potencialmente interessado de apoiadores a Felipe Neto. Para além da discussão política gerada, a abertura à leitura de conteúdo LGBT+ pode ter sido propositalmente provocada por Felipe Neto, e um efeito colateral da ação de censura protagonizada por Crivella.

\section{Criança(s): quem as educa?}

O cluster que se forma com os termos "criança" e "crianças" apresenta uma série de linhas discursivas que merecem atenção. Sua associação ao adjetivo "inocentes" e aos verbos "cuidar" e "ensinar" posiciona o infante como um sujeito vulnerável. É a partir dessa premissa que surgem as conexões com os vocábulos "governo", "estatuto", "política" e "responsável", atribuindo ao Estado a responsabilidade de defender as crianças. Nesse mesmo sentido, aparecem os termos "pais" e "filhos" em uma série de nós que se constituem a partir da mesma lógica de cuidado e vigilância. De fato, as crianças são responsabilidade do Estado, da sociedade como um todo e da família. Porém, é importante discutir qual o suposto "perigo" (palavra também presente no cluster) que incide sobre as crianças e, mais além, pontuar qual a definição de infância que nos norteia.

O conceito de infância pode ser considerado uma invenção da contemporaneidade (Ariès, 2006). Baseado no senso comum, a infância era caracterizada pela dependência, ingenuidade e falta de maturidade, argumentos que aparecem com força semântica no cluster e que se constroem com característica conclusiva, considerando a presença do termo "então" nos nós observados. 
No campo teórico, o significado de infância segue tradicionalmente caminhos essencialistas, delimitando fases a partir da divisão etária. Piaget (1978) propõe uma divisão em quatro estágios, sendo no das operações concretas (7 aos 12 anos) que a criança se torna leitora autônoma de conteúdo e, potencialmente, está apta a distinguir a realidade da fantasia. Extrapolando essa perspectiva, a abordagem proposta pela sociologia da infância defende que outros aspectos, para além da faixa etária, como variações demográficas, relações econômicas, étnicas e dispositivos simbólicos, são determinantes para posicionar o lugar da criança na sociedade e seus modos de socialização (Corsaro, 2002).

Retomando a indagação anterior acerca dos "perigos" que ameaçam as crianças, alicerçada na discussão proposta sobre a infância, buscamos algumas respostas nos termos que se apresentam no cluster. Encontramos pistas nos vocábulos "cultura", "educação", "influência", "desserviço", "impor", "inapropriado". Ainda que alguns nós desestabilizem o discurso principal com a presença da palavra "preconceituosos", a prevalência nesse cluster é de argumentos que dividem cultura e educação para um lado e a influência de conteúdos com temática LGBT+ para o outro. Mais além, o termo LGBT+ foi aqui inserido a partir de um movimento interpretativo do que os comentários posicionam como "conteúdo inapropriado", ou termos similares -, argumento contestado por outra parte de usuários que afirma "não" se tratar de "pornografia".

De forma conclusiva, as construções de sentido analisadas indicam que "educação" e "educar" se associam aos verbos "ler" (em diferentes conjugações) e "estudar" e ao substantivo "literatura", em nós que se formam com os termos "filtrar", "acesso", "texto" e "atenção". O sentido dos comentários desta linha discursiva se torna claro quando observamos, muito próximos da palavra "criança", os termos "cedo" e "crescer", demonstrando que as crianças ainda não estariam aptas a consumir o conteúdo censurado, um "desserviço" ao ato de educar. A junção das ideias presentes nos comentários nos direciona a deduzir que o beijo entre dois personagens masculinos, ilustrado na história em quadrinhos em questão, extrapola a demonstração de afeto e, aqui, é lido como "inapropriado" para o público infantojuvenil, revelando que qualquer ato que remeta a comportamentos não hegemônicos no que concerne à sexualidade deveria apartar-se das crianças, contribuindo para a manutenção da heteronormatividade.

\section{LGBT+: em defesa da diversidade sexual}

A palavra "LGBT" é a mais central da rede, explicitando a temática geral dos comentários. Próximo a ela, estão presentes ligações semânticas com os vocábulos "censura", "diferente", "errado", "causa" e "comunidade", demonstrando um discurso de aceitação e de sentido de pertencimento ou simpatia a um grupo, assim como a reflexão em torno do ocorrido como forma de censura. A palavra "acho" se apresenta com força semântica, evidenciando o tom opinativo dos comentários. O advérbio "não" ou apenas " $n$ " faz forte conexão a LGBT, mas por ser precedido do pronome interrogativo "por que" - escrito prioritariamente como "pq" identificamos que impera o questionamento "por que não?". Assim, os comentários nesse cluster tendem a indagar o preconceito e especificamente a "homofobia", termo com menos conexões semânticas que aparece ainda associado ao cluster em questão e diretamente conectado às palavras "crime" e "cura".

Outros comentários encontrados na correlação "pq" e "nao" / " $\mathrm{n}$ " foram de posicionamento negativo, questionando as intenções do youtuber com o gasto de um valor que poderia ser usado em causas consideradas pelos usuários mais relevantes que a representatividade LGBT+ (lésbicas, gays, bissexuais, transexuais e mais).

A partir desses resultados, entendemos que tanto "LGBT" como "homofobia" são termos utilizados prioritariamente por pessoas que se posicionam positivamente à liberdade de uma expressão de gênero e de orientação sexual plurais. Partimos do conceito de cultura como cenário de práticas e contradições intrínsecas às diversas esferas sociais. Nessas arenas, as noções de hegemonia e contra-hegemonia tornam-se relevantes. Para Williams (1979), sob lentes 
culturalistas, o hegemônico é dominante e constitui um modo de vida ou visão de mundo constantemente atualizado.

$\mathrm{Na}$ outra ponta, encontra-se a contra-hegemonia, a qual constrói outras formas de política e cultura que são "rompimentos significativos em relação a estes" (Williams, 1979, p. 117). As vivências de pessoas LGBT+ seriam, assim, expressões contra-hegemônicas que desestabilizam as normas sociais e a "heterossexualidade compulsória" (Butler, 2003).

Nesse jogo, é justamente a performance dessas identidades dissidentes que subverte as normas de gênero e sexualidade em sociedade, de uma coerência conjuntural entre sexo, gênero e desejo e a partir das influências e coerções do ambiente coletivo. O beijo entre dois rapazes ilustrado no HQ Vingadores, a cruzada das crianças representa não somente a possibilidade de desejar pessoas do mesmo sexo biológico, como também de que esse sentimento se torne socialmente aceito desde a infância. Através da representação, reforçamos a existência de identidades múltiplas e ampliamos as possibilidades de autoidentificação. Assim, as representações são performáticas, pois fazem parte de uma rede mais ampla de atos linguísticos e imagéticos que, em seu conjunto, contribuem para definir ou reforçar a identidade que supostamente estamos apenas descrevendo ou ilustrando (Woodward, 2011).

A relação entre as causas LGBT+ e a infância não apareceu nos comentários analisados. O foco das discussões deste cluster esteve centrado em opiniões que rechaçam a censura, de modo geral, e a homofobia, e que celebram o pertencimento a um grupo social. Em menor grau, encontram-se comentários que tratam da vivência dessa comunidade como algo negativo, sem que a sigla seja mencionada.

Sobre o sentimento de pertencimento, pontuamos que a visibilidade que as identidades LGBT+ ganharam, especialmente após a ascensão dos movimentos sociais dos anos 1960, foi determinante para a identidade cultural dos indivíduos pertencentes a grupos sociais oprimidos ou marginalizados (Woodward, 2011). Nesse contexto, se outrora a categorização de um grupo marcado de sujeitos com comportamento homossexual os posicionou em desviantes da norma, com destino à segregação social ou ocultação de suas identidades (Louro, 2004) ambos os lugares incômodos para se permanecer -, no atual contexto, é justamente a união desses movimentos que permite a integração dos sujeitos, mesmo que ainda, em muitas esferas, socialmente segregados. $\mathrm{O}$ rechaço ao preconceito e, em especial, à homofobia e à própria homofobia como expressão de ódio são sintomáticos de uma sociedade de contrastes. Por um lado, alguns setores sociais demonstram uma crescente aceitação da pluralidade sexual e de gênero; por outro, setores tradicionais e conservadores renovam e recrudescem seus ataques, com manifestações de violência física e simbólica.

Se, nos comentários analisados ao longo desta pesquisa empírica, não observamos qualquer referência ao título ou ao conteúdo das obras distribuídas pelo youtuber como embasamento do discurso proferido, vemo-nos instigadas e trazer para este espaço exemplos dos próprios livros de temática LGBT+ entregues gratuitamente na Bienal que poderiam perfeitamente ilustrar o teor dessas postagens. Em O garoto quase atropelado, do escritor Vinícius Grossos e publicado por Faro Editorial, um garoto solitário e sem nome vivencia uma depressão profunda. A ausência de um nome contribui para posicionar sua situação de abandono social em um lugar comum. Seu encontro com outros jovens também em condição de exclusão exorciza demônios, estes sim de fácil identificação e letras garrafais. A violência, o abandono familiar e a homofobia estão entre eles. Tão difícil como essas experiências de vida está o aprisionamento de sentimentos guardados típicos do isolamento social.

Como uma resposta para esses sentimentos que tendem a se manter ocultos da sociedade, garantindo a manutenção do sistema hegemônico, em Confissões de um garoto tímido, nerd $e$ (ligeiramente) apaixonado, da escritora Thalita Rebouças e publicado pela Editora Arqueiro, para além de uma trama que envolve as descobertas do primeiro amor adolescente, no sentido mais plural, encontramos mensagens de libertação contra um modelo pré-definido que impõe rótulos. Ainda que não haja teorização na construção dessas mensagens proferidas por personagens da narrativa, elas se alinham às reivindicações políticas do movimento queer contra forças coercitivas que buscam enquadrar as identidades aos modelos pré-existentes. $\mathrm{O}$ termo, 
que em inglês significa "estranho" ou "esquisito", é ressignificado e o "diferente" passa a ser celebrado, representando a diferença que não pretende ser assimilada ou tolerada, muito mais transgressora e perturbadora. $\mathrm{O}$ grande desafio que se delineia é não somente assumir a multiplicidade dos papéis de gênero e sexuais, mas admitir que as fronteiras são constantemente atravessadas (Louro, 2004). Provavelmente tanto a teoria como a sua representação em forma de narrativa literária aqui ilustrada são modos de reafirmar a expressão "Por que não" - ou "Pq não? - tão frequente nos comentários analisados.

\section{Deus acima de tudo}

O termo "amor" também se apresenta no centro do mapa semântico e com forte rede de conexões, demonstrando como seus nós se interconectam a mais de um cluster. Por um lado, argumentos posicionam a palavra associada a "preconceito", "homofobia", "LGBT" e "respeito" em um discurso de defesa evidente à diversidade sexual. Essa linha discursiva já foi discutida no cluster anterior e a palavra "amor" se soma aos argumentos, agregando valores morais à racionalidade que ali prevalecia, especialmente quando a ela se associa as palavras "Deus", "abençoe" e "próximo". Por outro, ela se relaciona a termos como "Homem" e "mulher" e a diversos vocábulos de cunho religiosos, como "Deus" e "bíblia". É para esse discurso que o nosso olhar se volta.

Com a palavra Deus, para além da expressão "pelo amor de Deus" e sua relação com os termos anteriormente mencionados, observamos relações semânticas com personagens bíblicos, como "Adão" e "Eva" (expressos com frequência apenas através do binarismo "homem"/"mulher") e com as palavras "pecado" e "pecadores", "verdadeiro" e "criou". Aqui fica claro um posicionamento que confronta a pluralidade de gênero e à homossexualidade como orientação.

Para além do criacionismo, a história de Adão e Eva perpetua as relações de poder e divisão de papéis entre o homem e a mulher, os quais regem as sociedades de forma mais ou menos literal. Não nos cabe, para esta análise, discutir o patriarcado devido a sua complexidade, no entanto, está nessa estrutura social o norte da linha discursiva que pretendemos aqui discutir. A onipotência de Deus se expressa nos comentários quando os argumentos que se constroem se baseiam na "verdadeira criação". São esses papéis sociais que modulam a estrutura da "família" e rechaçam qualquer outro modelo social e, entre os mais odiados (e temidos), a homossexualidade.

A presença da palavra "ordem" demonstra que o sentido é de demarcação do binarismo "homem" /"mulher", direcionando a heterossexualidade como único modo de vida. "Pecado" e "pecadores", muitas vezes substituídos por outros termos de conotação similar, como a expressão "contra os princípios de Deus", apresentam-se como violação de um preceito religioso, aqui, o pecado da luxúria - qualquer prática sexual que não tenha como finalidade a reprodução.

A força desse argumento não pode ser medida por sua subjetividade, no entanto, dados sobre os hábitos de leitura dos brasileiros são reveladores. De acordo com a "Pesquisa Retratos da Leitura no Brasil" (Instituto Pró-Livro, 2016), 42\% dos leitores brasileiros - pessoas que declararam ter lido ao menos um livro ou partes dele nos últimos 3 meses - afirmaram ter lido a Bíblia, e 22\%, livros religiosos. Assim, "o livro-referência supremo ligado à Igreja, o primeiro dos quais a Bíblia, serve, então, para desqualificar e proscrever todos os livros que se afastem dos valores que o livro em si veicula" (Eco e Carrière, 2010, p. 254).

As consequências sociais desses dispositivos de controle, como sugere Foucault (1988), foram devastadoras para aqueles considerados desviantes das normas religiosas vigentes, os "pecadores". Da combinação entre esforços religiosos e médicos (patologizantes) para garantir a "ordem", uma série de experimentos ganharam forma para "transformar" homossexuais em indivíduos heterossexuais (Badinter, 1993). A palavra "cura" também fez parte dos comentários analisados, ainda que com poucos nós e menor força semântica. Mas sua presença nos leva a pontuar que ainda hoje - e talvez em um movimento de retomada com a ascensão do fundamentalismo religioso atrelado à política - esteja em voga a "crença" de uma "cura" para a homossexualidade. Essa problemática é tratada em Boy erased, de Garrard Conley, publicado pela editora Intrínseca. O livro biográfico foi distribuído gratuitamente por Felipe Neto na Bienal e revisita as memórias do autor, de um doloroso período em que foi submetido a um 
programa de "conversão" que prometia "curá-lo" de sua homossexualidade. Filho de um pastor da Igreja Batista, ele foi criado em uma pequena cidade conservadora dos Estados Unidos. No "Refúgio", o adolescente teve aulas de como "ser homem", a partir de interpretações da Bíblia, induzindo-o ao medo e à culpa. Segundo o autor, a obra foi escrita para ajudar outros homossexuais que são submetidos à tortura e à repressão.

\section{Considerações finais}

Nossa trajetória teórica e empírica nos permitiu chegar a algumas considerações. Discorremos acerca das relações de poder e sobre o aspecto político intrínsecos ao objeto livresco, palco de disputas no campo ideológico e com fortes marcas do que Habermas (1981) denomina "mundo da vida". Nesse embate de forças, muitas vezes desiguais, a dominação abriu espaço para o autoritarismo - e suas faces coercitivas - direcionado ao silenciamento de conteúdos literários que, potencialmente, corroboram para a emancipação social.

Direcionamos os holofotes à literatura infantojuvenil por acreditarmos tratar-se de um campo fecundo que, dando vazão à fantasia, permite a construção de discursos implícitos que, em momentos mais ou menos específicos da história, esquivaram-se da censura e, ainda, plantaram ideias vanguardistas e renovadoras.

Sobre esses períodos, demarcamos a ditadura militar brasileira como repressora em um sentido amplo e, entre as formas de arte censuradas, a literatura ganhou foco. A proibição de diversas publicações como instrumento de controle social, político e cultural descortinaram a intolerância a modos diversos de pensar e agir, regida por uma moralidade caraterística do conservadorismo religioso.

Alicerçado no mesmo pensamento conservador que décadas atrás deu suporte ao golpe militar, observamos a ameaça à livre expressão da atividade intelectual ganhar contornos hodiernos e, também, abrir terreno para manifestos em defesa à democracia. Em nosso exercício empírico, percebemos que, embora prevalecesse o tom de apoio à liberdade de expressão e, mais além, à comunidade LGBT+, mensagens conservadoras em defesa da heterossexualidade compulsória, por vezes moduladas por valores morais cristãos, inundaram a rede, especificamente nos comentários ao vídeo objeto deste estudo. Se, aparentemente, a prevalência de manifestações de apoio à livre expressão aponta qual o lado dessa disputa ideológica possui mais força, outras variantes desestabilizam essa lógica. Primeiramente, o vídeo analisado está inserido em um canal específico, do idealizador da ação e, assim, o conteúdo transita muito mais fluidamente entre seus seguidores do que entre seus opositores. Ademais, partindo para um contexto macro, a eleição de um presidente da República ultraconservador, aliado ao fundamentalismo religioso e ao militarismo, tem muito a asseverar.

As incertezas acerca dos caminhos futuros reverberaram nos comentários analisados. Devido ao limite proposto para este artigo, não nos debruçamos em seu conteúdo, porém, parece-nos pertinente encerrar esse texto com indagações que ali se fizeram presentes. Em um tom apocalíptico, aparece a palavra "Brasil", diretamente relacionada a "pior", "país", "mundo", "medo", "ditadura", "retrocesso" e ao verbo "acontecendo", demonstrando uma preocupação e um temor acerca dos caminhos que o país trilha. As palavras "democracia", "união" e os verbos "espero" e "lutar" trazem a "esperança" para o cenário ou ao menos uma vontade de mudança.

Refletimos que, embora o poder institucionalizado - na figura do presidente da República e seus aliados - signifique a vitória do conservadorismo calcado em valores morais cristãos, historicamente machista e homofóbico, o efeito rebote, de resistência e de defesa a ações afirmativas, materializa-se nas diversas esferas sociais.

A metáfora das páginas em branco sintetiza a concepção dessas arenas. Em resposta à nulificação do valor do livro como suporte de conhecimento, proferida por Bolsonaro - "livros têm muita coisa escrita" -, um livro viraliza nas redes digitais ao listar motivos para confiar em Bolsonaro com 188 páginas em branco (Guimarães, 2019). Seja por meio das palavras, das 
narrativas visuais, ou da ausência de ambas, a literatura parece sempre encontrar os caminhos para sua permanência.

\section{Referências}

ABL critica censura do governo de Rondônia a livros de Machado, Nelson Rodrigues e outros (2020). O Globo, Rio de Janeiro, 7 fev. Disponível em: https://glo.bo/2JXoT03. Acesso em: 28 jan. 2020.

ABRELIVROS - ASSOCIAÇÃO BRASILEIRA DE EDITORES E PRODUTORES DE CONTEÚDO E TECNOLOGIA EDUCACIONAL (2017). MEC diz que vai recolher livro infantil de escolas por falar de incesto. São Paulo: Abrelivros, 8 jun. Disponível em: https:/ / bit.ly/2JP1e1D. Acesso em: 29 jan. 2020.

ARIÈS, Philippe (2006). História social da criança e da família. Rio de Janeiro: LTC.

BADINTER, Elisabeth (1993). XY: sobre a identidade masculina. Rio de Janeiro: Nova Fronteira.

BASTIAN, Mathieu et al. (2009). Gephi: an open source software for exploring and manipulating networks. Disponível em: https://gephi.org/publications/gephi-bastian-feb09.pdf. Acesso em: 4 fev. 2020.

BORDINI, Maria da Glória (1998). A literatura infantil nos anos 80. In: SERRA, Elizabeth D’Angelo (org.). 30 anos de literatura para crianças e jovens: algumas leituras. Campinas: Mercado de Letras.

BUTLER, Judith (2003). Problemas de gênero: feminismo e subversão da identidade. Tradução de Renato Aguiar. Rio de Janeiro: Civilização Brasileira.

CHARTIER, Roger (2004). Conversa com Roger Chartier. [Entrevista a] Isabel Lustosa. Observatório da Imprensa, São Paulo, n. 304, 23 nov. Disponível em: https:/ / bit.ly/3lkwfIN. Acesso em: 28 jan. 2020.

CORSARO, William A. (1997). A reprodução interpretativa no brincar ao "faz-de-conta" das crianças. Revista Educação, Sociedade e Culturas, n. 17, p. 113-134.

DANOWSKI, James (1993). Network analysis of message content. In: DERVIN, Brenda; VOIGHT, Melvin J. (org.). Progress in communication sciences. New Jersey: Ablex Publishing. v. 7, p. 198-221.

ECO, Umberto; CARRIÈRE, Jean-Claude (2010). Não contem com o fim do livro. Tradução de André Telles. Rio de Janeiro: Record.

FOUCAULT, Michel (1988). História da sexualidade I: a vontade de saber. Rio de Janeiro: Eições Graal.

GUIMARÃES, Hellen (2019). Livro viraliza nas redes ao listar motivos para confiar em Bolsonaro com 188 páginas em branco. O Globo, Rio de Janeiro, 14 ago. Disponível em: https://glo.bo/32wfpiN. Acesso em: 29 fev. 2020.

HABERMAS, Jürgen (1981). Teoria do agir comunicativo: sobre a crítica da razão funcionalista. São Paulo: WMF Martins Fontes. v. 2.

INSTITUTO PRÓ-LIVRO (2016). Pesquisa Retratos da Leitura do Brasil. São Paulo: IPL, mar. Disponível em: https:/ / bit.ly/3ncBk6t. Acesso em: 29 dev. 2020.

INSTITUTO VLADIMIR HERZOG (s.d.). Memórias da ditadura. São Paulo: Instituto Vladimir Herzog. Disponível em: http://memoriasdaditadura.org.br. Acesso em: 274 jan. 2020.

JUCÁ, Beatriz. Justiça veta censura homofóbica de Crivella na Bienal do Livro do Rio. (2019). El País, São Paulo, 7 set. Disponível em: https:/ / bit.ly/38OcJko. Acesso em: 28 jan. 2020.

LAJOLO, Marisa; ZILBERMAN, Regina (2017). Literatura infantil brasileira: uma nova outra história. Curitiba: PUCPress; FTD.

LOURO, Guacira Lopes (2004). Um corpo estranho: ensaios sobre sexualidade e teoria queer. Belo Horizonte: Autêntica.

MALTA, Renata; AMADO, Aianne; MEIRELLES, Pedro (2019). \#Casamentoreal: uma análise sociocultural a partir de postagens no Twitter. Revista Fronteiras, v. 21, n. 3, p. 28-40.

MANGUEL, Alberto (2010). Uma história da leitura. São Paulo: Companhia das Letras. 
MANGUEL, Alberto (2018). Ler é um ato de poder. Vídeo (5m34s). Publicado no site Fronteiras do Pensamento. Disponível em: https://www.fronteiras.com/videos/ler-e-um-ato-de-poder. Acesso em: 24 fev. 2020.

MARTIN, Henry-Jean; FEBVRE, Lucien (1992). O aparecimento do livro. São Paulo: Hucitec; Ed.Unesp.

MENDONÇA, Heloísa (2017). Queermuseu: o dia em que a intolerância pegou uma exposição para Cristo. El País, São Paulo, 13 set. Disponível em: https://bit.ly/3pb0wfj. Acesso em: 28 jan. 2020.

MORAES, Carlos; LAJOLO, Marisa (1995). A expansão da literatura infantil. In: BASTOS, Dau (org.). Ana $\mathcal{E}$ Ruth. Rio de Janeiro: Salamandra.

NETO, Felipe (2019). Censura na Bienal!. Vídeo (5m38s). Publicado no canal de Felipe Neto no Youtube. Disponível em: https://www.youtube.com/watch?v=meqsHqP4Qw4. Acesso em: 2 fev. 2020.

OITO livros que sofreram tentativa de censura recentemente no Brasil (2019). Biblioo - Cultura Informacional, 13 set. Disponível em: https:// bit.ly/3pD79Hq. Acesso em: 28 jan. 2020.

PIAGET, Jean (1978). O nascimento da inteligência na criança. Tradução de Álvaro Cabral. Rio de Janeiro: Zahar.

QUINTANA, Mario (2005). Caderno H. 2. ed. São Paulo: Globo.

RECUERO, Raquel (2014). Conversação em rede: comunicação mediada pelo computador e redes sociais na internet. 2. ed. Porto Alegre: Sulina.

RIEDER, Bernhard (2015). YouTube Data Tools. Version 1.11. Software. Disponível em: https://tools.digitalmethods.net/netvizz/youtube/. Acesso em: 2 fev. 2020

WILLIAMS, Raymond (1979). Marxismo e literatura. Rio de Janeiro: Zahar.

WOODWARD, Kathryn (2011). Identidade e diferença: uma introdução teórica e conceitual. In: SILVA, Tomaz Tadeu da (org.). Identidade e diferença: a perspectiva dos estudos culturais. 10. ed. Petrópolis: Vozes. p. 7-72. 